\begin{tabular}{|c|c|}
\hline ב & $\begin{array}{c}\text { International Journal of Current Research } \\
\text { and Academic Review }\end{array}$ \\
\hline $\begin{array}{c}\text { XCELLENT } \\
\text { XCELISHERS }\end{array}$ & $\begin{array}{c}\text { ISSN: } 2347-3215 \text { (Online) } \because,: \text { Volume } 5 \\
\text { Journal homepage: http://www.ijcrar.com } 8 \text { (August-2017) }\end{array}$ \\
\hline
\end{tabular}

doi: https://doi.org/10.20546/ijcrar.2017.508.0014

\title{
Effectiveness of Life Skills Training Package (LSTP) on Academic Performance among Children Residing in Selected Orphanages, Tamil Nadu, India
}

\author{
Joseph Jeganathan $^{1^{*}}$ and K. Reddemma ${ }^{2}$
}

${ }^{I}$ Department of Mental Health Nursing, Aladi Aruna College of Nursing, Alangulam, Tirunelvelli district, Tamil Nadu, India

${ }^{2}$ Nodal office, National consortium for PhD Nursing, St. Johns College of Nursing, Bangalore-34, Karnataka, India

*Corresponding author

\begin{abstract}
Adolescence refers to the long transitional developmental period between childhood and adulthood and to a maturational developmental process involving major physical, psychological, cognitive, and social transformations. It is estimated that 153 million children worldwide, ranging from infants to teenagers, have lost one or both parents. Over 7 million children are in institutional care worldwide. Research studies have shown various psychosocial factors and skills deficits that are the mediating to the development of various behavioral, psychological as well as health related problems among vulnerable children. This study was conducted to evaluate the effectiveness of Life Skills Training package (LSTP) on Academic Performance of children residing in selected orphanages in Tamil Nadu. This study adopted a Quasi-experimental Pretestposttest control group design. The present study was conducted at Sri Kanyakumari Gurukulam Children's Home, Zion Bethel Home, Loving Hands Trust India, Rehoboth Happy Home, Annai Theresa Children's Home, Indian Revival Ministries Children's Home, Tirunelvelli District, Tamil Nadu. Children with age twelve years to eighteen years old comprise the sample for the present study, totally 120 children were selected randomly, from the five selected orphanages and 60 children from the selected orphanages were assigned to experimental group, and 60 children to control group. Data was collected using Socio-demographic data sheet, and Academic record of the children. Then LSTP was administered to the experimental group and the post assessment data were collected at different time interval one week, one month, three month and six month after the intervention from both the groups. Majority in experimental group 68\% and in control group, 53\% children were in the age group between 12-14 years. In experimental group majority of the children were male $60 \%$. Similarly in control group 58\% were males. The pretest Mean score and SD of academic performance in experimental group was $66.3 \pm 14.3$ and in control group 63.0 \pm 13.9 . The post-test Mean score and SD of academic performance in experimental group was $66.7 \pm 14.4$ and in control group $62.4 \pm 12.7$. Between groups at pre assessment, the mean and SD of experimental group $(66.3 \pm 14.3)$ is higher than in control group $(63.0 \pm 13.9)$. The present study finding revealed that there is an impact of Life Skills Training package on academic performance of children under residential care settings
\end{abstract}

\section{Article Info}

Accepted: 30 July 2017

Available Online: 20 August 2017

\section{Keywords}

Children in orphanages, Life Skills Training Package and Academic Performance 


\section{Introduction}

Adolescence refers to the long transitional developmental period between childhood and adulthood and to a maturational developmental process involving major physical, psychological, cognitive, and social transformations ${ }^{1}$. Adolescents' age range from 12-18 years. $^{2}$ it is estimated that in India the Adolescent population between age group 10-19 years were 253.2 million (20.9\%); girls were 119.8 (47.3\%) and boys were 133.4 (52.7\%). In Tamil Nadu Adolescent $17.2 \%$ of the entire population. ${ }^{3,4}$

It is estimated that 153 million children worldwide, ranging from infants to teenagers, have lost one or both parents. Over 7 million children are in institutional care worldwide. Asia is home to the large number (60 million) of orphaned children in the world; 30 million children in East Asia suffer from at least one severe deprivation. An estimated 31 million children in India, aged 0-17 years, are orphaned and abandoned (UNICEF). ${ }^{5,6}$ Research studies have shown various psychosocial factors and skills deficits that are the mediating to the development of various behavioral, psychological as well as health related problems among vulnerable children. Low self-esteem, poor communication skills and problem solving skills, poor decision making skills and lack of assertiveness were found to be linked with delinquency ${ }^{7}$, school dropouts ${ }^{8}$, smoking and drug abuse ${ }^{9,10}$, teenage pregnancy ${ }^{11,126}$, suicidal thoughts ${ }^{13}$ and health problems ${ }^{14}$.

Changes in life styles are inevitable and among the most affected are children and adolescents. In any society, the rapidly changing social, moral, ethical and religious values demands certain life styles especially among young adolescents. Moreover, these changes interfere with their physical, psychological and social health resulting into involvement of high-risk behaviors - such as drug abuse, teenage pregnancy, AIDS, delinquency, dropping out of the school, suicides, early sexual experimentation, abuse and neglect and homicide, The young adolescents of today have less chance for successfully reaching adulthood than their counter parts lived during any part of previous century and they requires a set of skills for successful adaptation. ${ }^{15}$

The author proposed the existence of eight human intelligences that takes place into account the wide range of human thinking capacities. These include linguistic, logical/mathematical, spatial, kinesthetic, naturalistic interpersonal and intrapersonal intelligence. The theory of multiple intelligences has implications for educational systems and for incorporating life skills approach to promotion and prevention. ${ }^{16}$

Life skills refer to the competencies that an individual needs for sustaining and enriching life ${ }^{17}$. Powell (1995) defines life skills as the life coping skills consonant with the developmental tasks of the basic human development processes, namely those skills necessary to perform tasks for a given age and gender in the following areas of human development - psychological, physical, sexual, vocational, cognitive, moral, ego and emotional ${ }^{18}$. Darden et al., (1996) defined life skills as all those skills and knowledge prerequisite to development of skills in addition to the academic skills that are necessary for effective living ${ }^{19}$.Life skills education enables adolescents to learn and practice skills, as it is based on student centered and activity oriented methodology. Different methods that can be used to enhance Life Skills among children such as Class discussions, Brainstorming, Demonstration and guided practice, Role plays Audio and visual activities, e.g., arts, music, theatre, dance, Small groups, Educational games and simulations, Case studies, Storytelling, Debates, Decision mapping or problem trees. Successful implementation of life skills education program have shown significant improvement in psychosocial wellbeing like a significant improvement on academic achievement, ${ }^{20}$ Life skills are also important to prevent specific problems to avoid risky behaviors and overcome particular barriers to healthy development. The problems such as Smoking, Drug and alcohol abuse, Bullying and violence, Delinquency, Gender discrimination, HIV/AIDS, Child abuse, etc ${ }^{21}$. Considering these over the last decade there has been an increased interest in life skills among mental health professionals, Psychiatric Nurses, social workers and psychologists to provide today's children and adolescents with a set of skills for successful adaptation. Hence this study was conducted to evaluate the effectiveness of Life Skills Training Package (LSTP) on Academic Performance of children residing in selected orphanages

\section{Materials and Methods}

This study adopted a Quasi-experimental Pretest-posttest control group design. The present study was conducted at five selected orphanages in Tamil Nadu. Sri Kanyakumari Gurukulam Children's Home, Zion Bethel Home, Loving Hands Trust India, Rehoboth Happy 
Home, Annai Theresa Children's Home, Indian Revival Ministries Children's Home, Tirunelvelli District, Tamil Nadu. Children with age twelve years to eighteen years old comprise the sample for the present study, totally 120 children were selected randomly from the five selected orphanages and 60 children from the selected orphanages were assigned to experimental group, and 60 children to control group. Data was collected using Socialdemographic data sheet developed by the researcher, it dealt with details such as age, gender, religion, family type, family income, birth order, number of siblings, reason for placement, duration of stay in orphanage, mode of admission, visitors, frequency of visit, background, educational status of child, over all academic achievement, support system, dietary habit, feeling stressed, study timings at the orphanage, child's attendance during the study hours, availability of teacher's during the study hours. And Academic record of the children issued by the School for assessing the Academic Performance. Data was collected in three phases. In first phase administrative permission from the Management and the In-charge of the orphanages was obtained. An informed assent was obtained from the children of the both groups for the willingness to participate in the study. Children were randomly allocated to the experimental and control group. Finally pretest was conducted with the tools on both groups. In second phase the life skill training Package (LSTP) was implemented for 4 hour per day for 5 days for the experimental group and in third phase post intervention data was collected after one week, one month, three month and six month after Life Skill Training Package (LSTP) by using same tools used in pre-test tools for children of both groups. Data were analyzed by using SPSS 17th version. Descriptive and inferential statistics were performed, the repeated measures ANOVA to compare the scores of the tool of each group over the various time points (pre-intervention to 4 th follow up).

\section{Results and Discussion}

\section{Socio-demographic profile of Children under study}

With respect to the age, Majority in experimental group $68 \%$ and in control group, $53 \%$ children were in the age group between 12-14 years. In experimental group majority of the children were male $60 \%$. Similarly in control group majority were male i.e. 58\%. Regarding the religion in experimental group, $97 \%$ children belong to Hindu religion. In control group, $60 \%$ children belong to Hindu. In experimental group, 55\% of the children were belonging to nuclear type of family. In control group, $43 \%$ children were found to be having joint family. With respect to the family income experimental group, $42 \%$ monthly family income is within Rs.15003000. Some children with parents alive were also living in orphanage due to poverty. In control group, 23\% family income is above Rs.5000. In experimental group $40 \%$ children were first born child to their parents. In control group $42 \%$ children were belong to first order.

Regarding to the number of siblings, experimental group $33 \%$ children have more than three siblings. In control group $42 \%$ children were found to have one sibling. The reason for placement at the orphanage in experimental group 48\% children have lost either one of their parent, $7 \%$ children have lost both the parents, $38 \%$ children due to poverty and $7 \%$ children found to have parents separated. In control group 36\% children have lost either one of their parent, $18 \%$ children have lost both parents, $33 \%$ children due to poverty and $12 \%$ children found to have parents separated. In experimental group $38 \%$ children found to stay more than 5 years. In control group 38\% children found to stay between 3-5 years. In experimental group majority $68 \%$ and in control group $77 \%$ children were from rural areas. With regard to the educational status of the child. In experimental group majority $58 \%$ children were found to be in upper primary level, In control group 50\% children were found to be in high school level. In experimental group $50 \%$ children were below average. In control group 50\% children were found to be average in the studies. Regarding the study timing at the orphanage in experimental group $100 \%$ children were found to maintain the study timings at the orphanage. In control group majority $83 \%$ children were found to maintain the study timings at the orphanage. With regard to the attendance during the study hours majority in experimental group, $98 \%$ and in control group $83 \%$ children were found to have regular attendance. In experimental group, $68 \%$ children were found to have teachers regularly during the study hours and $32 \%$ children were found to have no regular teachers during the study hours. In control group, $67 \%$ children were found to have teachers regularly and $33 \%$ children were found to have no regular teachers during the study hours.

\section{Impact of Life Skills Training Package on academic performance}

Table 1 shows the pre and posttest Mean scores and SD of academic performance of children in experimental and control group. The pre test Mean score and SD of academic performance in experimental group was 
$66.3 \pm 14.3$ and in control group 63.0 \pm 13.9 . A study conducted by Saraswati C, Hunshal, Gaonkar V (2008) reported that significant association between academic performance and social, emotional, and educational adjustment of institutionalized children ${ }^{22}$. In contrary, Nancy AS (2013) reported that orphanhood was not a significant predictor of worse educational outcomes or psychosocial wellbeing ${ }^{23}$. The post-test Mean score and
SD of academic performance in experimental group was $66.7 \pm 14.4$ and in control group $62.4 \pm 12.7$.

There was an improvement in the academic performance in the experimental group. Similarly Prajina.P.V and Godwin.J. (2015) reported that children possess less life skills and score comparatively less percentage of academic scores $^{24}$.

Fig.1 Pre and posttest mean scores of academic performance in experimental and control group

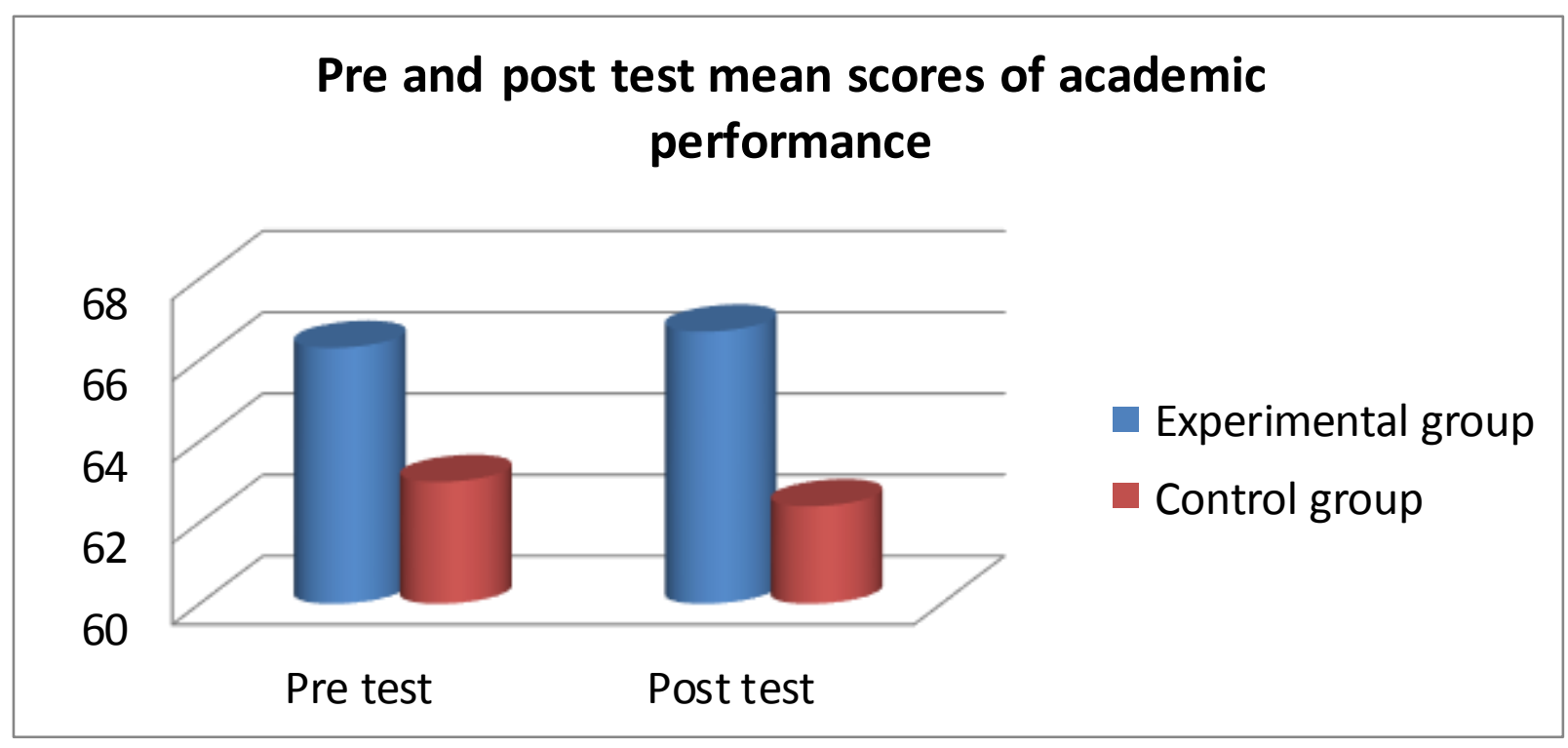

Fig.2 Between group comparison among pre, posttest-I, II, III and IV assessments of the children in experimental and control group on the scores of academic performance

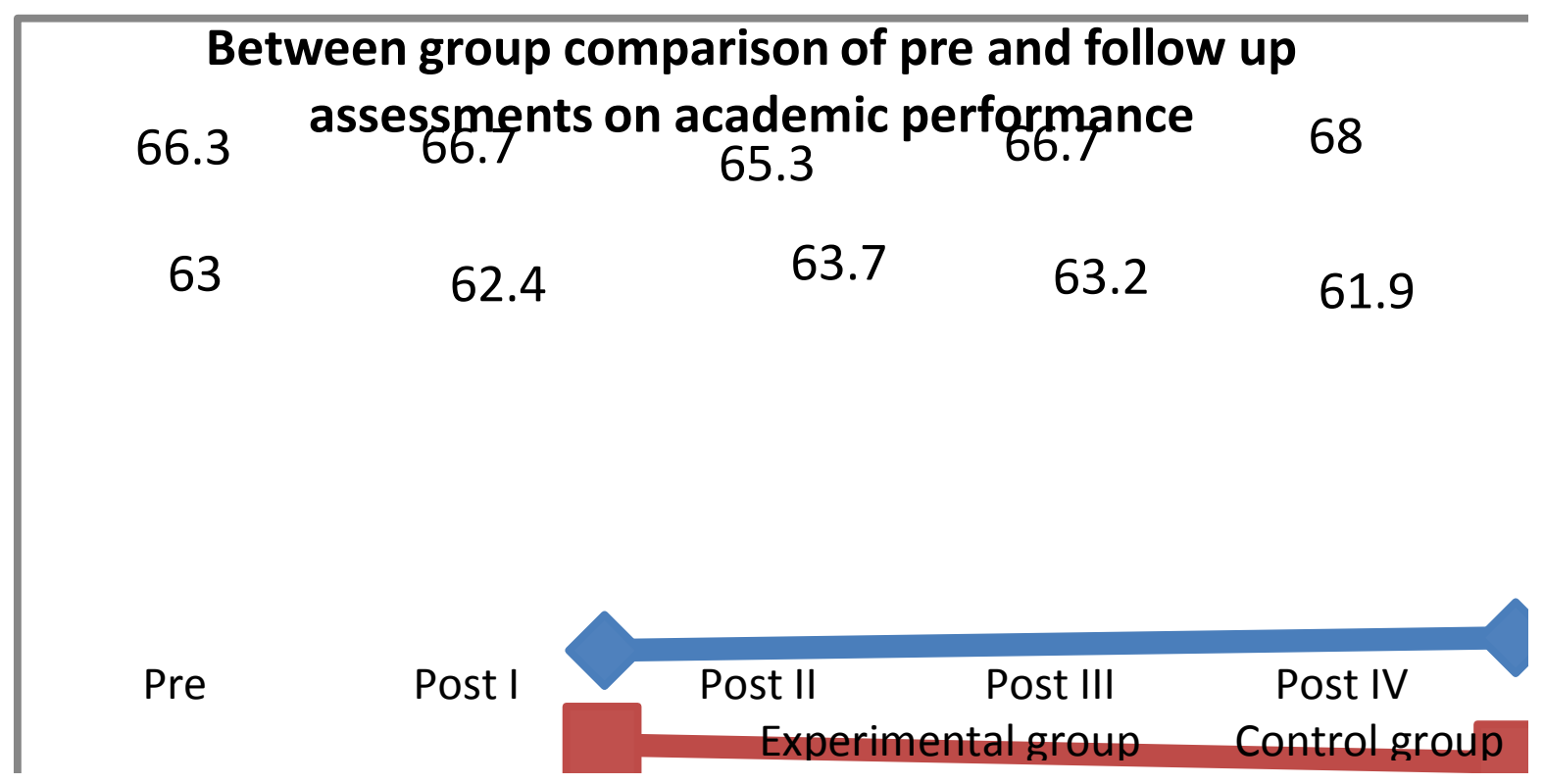


Fig.3 Pre- test scores (\%) in academic performance

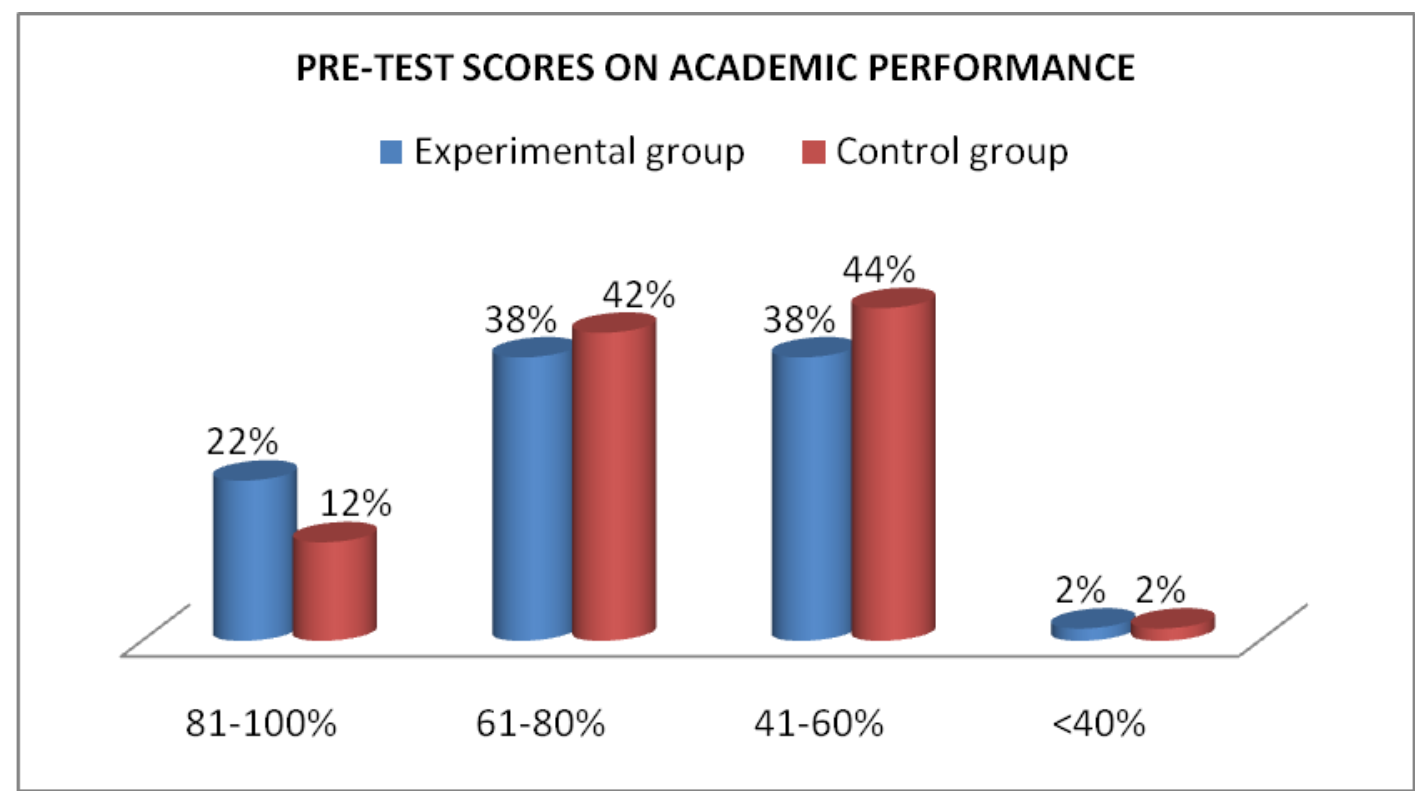

Fig.4 Post- test scores (\%) in academic performance

\section{POST TEST SCORES ON ACADEMIC PERFORMANCE}

Experimental group $\quad$ Control group

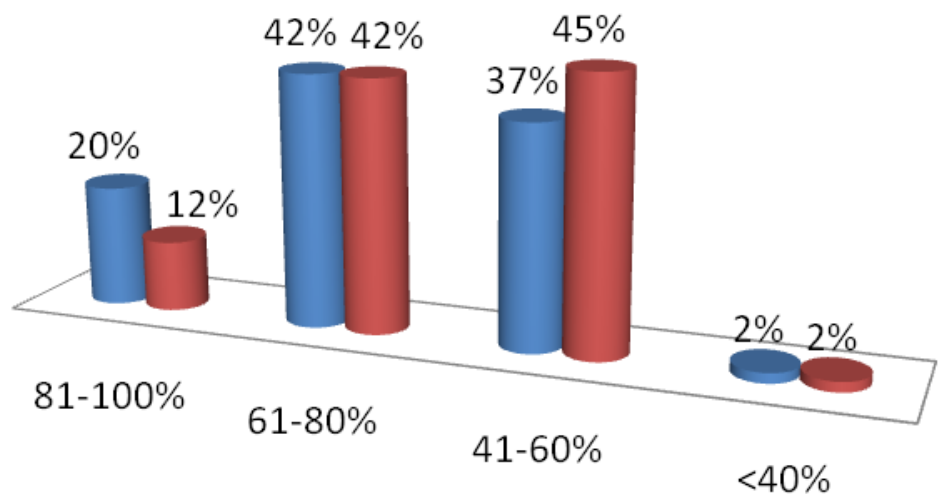

Table.1 Pre and posttest mean scores of academic performance in experimental group and control group ( $\mathrm{N}=120)$

\begin{tabular}{|l|l|l|l|l|}
\hline \multirow{2}{*}{ Assessment } & \multicolumn{3}{|l|}{ Experimental group (n=60) } & \multicolumn{2}{l|}{ Control group (n=60) } \\
\cline { 2 - 5 } & Mean & SD & Mean & SD \\
\hline Pre-test & 66.3 & 14.3 & 63.0 & 13.9 \\
\hline Post-test & 66.7 & 14.4 & 62.4 & 12.7 \\
\hline
\end{tabular}


Table.2 Between group comparison among pre, post and follow up assessments of the children in experimental and control group on the scores of academic performance $(\mathrm{N}=120)$

\begin{tabular}{|l|l|l|l|l|l|l|}
\hline \multirow{2}{*}{ Assessment } & \multicolumn{2}{|l|}{ Experimental group (n=60) } & \multicolumn{2}{l|}{ Control group (n=60) } & F-value & \multirow{2}{*}{ P-value } \\
\cline { 2 - 5 } & Mean & SD & Mean & SD & & \\
\hline Pre-Test & 66.3 & 14.3 & 63.0 & 13.9 & \multirow{2}{*}{2.83} & \multirow{2}{*}{0.095} \\
\hline Post I-Test & 66.7 & 14.4 & 62.4 & 12.7 & & \\
\hline Post II-Test & 65.3 & 13.6 & 63.7 & 13.8 & & \\
\hline Post III-Test & 66.7 & 14.1 & 63.2 & 14.1 & & \\
\cline { 1 - 4 } Post IV-Test & 68.0 & 14.0 & 61.9 & 12.7 & & \\
\hline
\end{tabular}

Table 2 highlights between group comparison among pre, post I, post II, post III and post IV assessments of the children in experimental and control group on the scores of academic performance.

The comparison between the experimental group and control group among the five levels of assessments Friedman repeated measures ANOVA reveals that there is no significant difference. Between groups at pre assessment, the mean and SD of experimental group $(66.3 \pm 14.3)$ is higher and in control group (63.0 \pm 13.9$)$. Within the experimental group in pre assessment the mean and SD was $66.3 \pm 14.3$ and at post IV assessment the mean and SD had increased to $68 \pm 14$ while in control group there was a decrease in the mean score $(61 \pm 12.7)$. However, the comparison difference between the groups shows that the children in experimental group had higher academic performance at both post and follow up assessments.

The above fig 3 reveals the pre-test scores on academic performance, $22 \%$ scored $81-100$ percentage, $38 \%$ scored 61-80 percentage and 38\% scored 41-60 percentage in their last exam by the children in experimental group. In control group 12\% scored 81-100 percentage, $42 \%$ scored $61-80$ percentage and $44 \%$ scored 41-60 percentage in their last exam.

The above fig 4 reveals the post-test scores on academic performance, $20 \%$ scored $81-100$ percentage, $42 \%$ scored 61-80 percentage and 37\% scored 41-60 percentage by the children in experimental group who attended the Life Skills Training Package. In control group 12\% scored $81-100$ percentage, $42 \%$ scored $61-80$ percentage and $45 \%$ scored $41-60$ percentage in their exam. There is no immediate change in the scores seen in the experimental group. However if they practice study skills taught to them in due course of time academic performance may improve.
There is a relationship between life skills and academic performance. Academic achievements among children who are living in difficult circumstances can be affected due to various factors. By giving life skills training the academic performance of the children can be improved.

\section{References}

Benjamin JS. Comprehensive Textbook of Psychiatry (2 Volume Set), Lippincott Williams \& Wilkins Publishers; 7th edition, 2000, p 5244-5245.

Bye L, Jussim L. A proposed model for the acquisition of social knowledge and social competence. Psychology in the Schools. 1993; 30:p $143-161$.

Cairns RB, Neckerman HJ, Cairns BD. Social networks and the shadows of synchrony. In G. R. Adams (Ed.), Biology of adolescent behavior and development (pp. 275 - 305). Thousand Oaks, CA: Sage. 1989.

Census of India 2011, Ministry of Home Affairs, India, 2013.

Choquet, M., Kovess V., and Poutignat, N. (1993). Suicidal thoughts among adolescents: An intercultural approach. Adolescence, 28 (111), 649 659.

Darden CA, Ginter EJ, Gazda GM. (1996). Life skills development scale (adolescent form): The theoretical and therapeutic relevance of life skills. Journal of Mental Health Counseling. 1996; 2, p142 - 163.

Duckes RL, Lorch BB. Concept of self-mediating factors and adolescent's deviance. Sociological Spectrum. 1989; 9(3):p301 - 319.

Gardner H. Frames of Mind: The theories of multiple intelligences, New York. Basic Books. 1993.

Hamburg DA, Takanishi, R. Great transitions: Preparing American youth for the 21st century - The role of research. Journal of Research on Adolescence.1996; 6:p 379 - 396.

http://www.censusindia.gov.in 
http://www.sos-usa.org/our-impact/childrensstatistics\#sthash.IX6EK2tO.dpuf

http://www.unicef.org/infobycountry/india_statistics.htm 1

Keddie A. Psychosocial factors associated with teenage pregnancy in Jamaica. Adolescence. 1992; 27(108):p 873 - 890.

Kumfer KL, Turner CW. The social ecological model of adolescent substance abuse: Implication for prevention. International Journal of the Addictions, 1990; 25(4):p 495 - 463.

Nancy AS. Orphans in zambia: program monitoring and evaluation practices and the association of external support with education status and psychosocial wellbeing, Submitted in partial fulfillment for the degree of Doctor of Public Health, Boston university school of public health, 2013

Pickworth G. Life skills training and career development from a career guidance perspective. Masters Dissertation, Pretoria, University of Pretoria. 1989.

Plotnick RD. The effects of attitudes on teenage premarital pregnancy and its resolution. American Sociological Review.1992; 57(6):p 800 - 811.

Powell MF. A program for life skills training through interdisciplinary group processes. Journal of Group

\section{How to cite this article:}

Joseph Jeganathan and Reddemma K. 2017. Effectiveness of Life Skills Training Package (LSTP) on Academic Performance among Children Residing in Selected Orphanages, Tamil Nadu. Int.J.Curr.Res.Aca.Rev. 5(8), 93-99.

doi: https://doi.org/10.20546/ijcrar.2017.508.014
Psychotherapy, Psychodrama, and Sociometry. 1995; 38(1), 23 - 34.

Prajina.P.V and Godwin. J. Premsingh., A Study On Life Skills In Relation To The Academic achievements Of Tribal Children. International Journal of Recent Scientific Research Vol. 6, Issue, 8, pp.5722-5724, August, 2015

Reza F. Effectiveness of Academic and Life Skills Instruction on the Freshmen Academic Achievement, J. Life Sci. Biomed. 2012; 2(4): 137 141.

Saraswati C, Hunshal, Gaonkar V. A Study on Adjustment of Institutionalized Children, Karnataka J. Agric. Sci. 2008; 21(4):p548-552.

Senven. Experience, reflection, reasoning or communication as a guide to belief and action 1996 available at www.criticalthinking.org/pages/defining-criticalthinking/410

Singh H, Mustapha N. Some factors associated with substance abuse among secondary school students in Trinida and Tobago. Drug Education. 1994; 24(1): p89-93.

The Gazette of India, Ministry of Law, Justice and Company Affairs, the Juvenile Justice (care and protection of children) act, 2000. 